\title{
Fundamental Modes of Operation for Mass Customization
}

\author{
Bart MacCarthy ${ }^{*}$, Philip G Brabazon, Jo Bramham \\ Mass Customization Research Centre, Nottingham University
}

\begin{abstract}
The concept of Mass Customization (MC) - producing customised goods for a mass market has received considerable attention in the research literature in recent years. However the literature is limited in providing an understanding of the content of MC strategies (the organizational structures, process technologies, etc., that are best in a particular environment) and the process of MC strategies (the sub-strategy that an enterprise should select and how they should go about implementing an $\mathrm{MC}$ strategy). In this paper six published classification schemes of relevance to Mass Customization are reviewed. The classification schemes are applied to five case studies of enterprises operating in an $\mathrm{MC}$ environment. The limitations of the schemes are analysed and their failure to distinguish key characteristics is highlighted. Analysis of the findings leads to the development of a taxonomy of operational modes for MC. Five fundamental modes of operation for Mass Customization are identified. These modes are described and justified and their application is illustrated by contrasting the information requirements of two modes. The potential of these modes to provide the foundations for detailed configurations models is discussed.
\end{abstract}

Keywords: Mass customization, taxonomy

\section{Introduction}

The concept of Mass Customization (MC) - producing customised goods for a mass market has received considerable attention in the research literature since it's identification by Davis (1987) and the influential book by Pine (1993). Mass Customization research is now at the stage of investigating and understanding how the concept can be operationalised across sectors. However, the scope of MC and hence the range of operations that qualify as MC is unclear. There is agreement in the literature that an important goal of MC is to obtain economies of scope that enable customised goods to be as affordable as mass produced goods (Pine 1993, Hart 1994, Alford et al. 2000, Tu et al. 2001), but beyond this agreement two viewpoints of MC are emerging. One view is that $\mathrm{MC}$ is a label to be given to manufacturing enterprises exhibiting particular structural characteristics, for example as observed in companies that are offering consumers personal discretion over the attributes of products that have otherwise been mass marketed to them in standard off-the-shelf configurations. The other view is that MC is a performance ideal - giving customers the opportunity to have a product 'any time they want it, anywhere they want it, any way they want it' - in a similar way that 'zero defects' is an ideal in respect of quality (Hart 1994). This latter view turns MC into a standard that is independent of context and so is relevant to customizing enterprises in general. A pragmatic interpretation of $\mathrm{MC}$ that blends the two viewpoints is that Mass Customization is different from pure customization in that some compromise, limitations and constraints are inevitable if mass characteristics - responsive, efficient,

\footnotetext{
* Corresponding author. Tel: +44-(0)-115-951-4025; fax +44-(0)-115-951-4000.

E-mail: bart.maccarthy@nottingham.ac.uk web:www.mcrcnottingham.org
} 
high throughput with high quality - are to be achieved and if premium prices are to be avoided (MacCarthy et al. 2002).

A unifying framework of MC is a goal of the research reported here and an open and pragmatic view of $\mathrm{MC}$ is a starting point. A further goal is the development of a suite of configuration models that satisfy the requirements identified by Bozarth and McDermott (1998) of providing understanding of the content of MC strategies (the organizational structures, process technologies, etc., that are best in a particular environment) and the process of MC strategies (the sub-strategy that an enterprise should select and how they should go about implementing the MC strategy).

A number of schemes for classifying MC enterprises, which are a precursor to configurations models, have been presented in the literature. However the suitability and potential of these schemes to provide the foundations for configuration models is unclear. In this paper we firstly review published classification schemes of relevance to Mass Customization. We then apply them to five case studies of enterprises operating in an MC environment in order to observe whether the schemes have the potential to group enterprises in a manner such that each group can benefit from similar organisational and technological solutions. Analysis of the findings leads to the development of a taxonomy of operational modes for MC. These modes are described and justified. The potential of these modes to provide the foundations for detailed configurations models is discussed.

\section{Classification of MC approaches}

Many researchers use the point where customization is undertaken as the primary dimension for differentiating MC operations. An influential work on the subject of customization which takes this view is by Lampel and Mintzberg (1996). They divide the value chain into four stages - design, fabrication, assembly and distribution - and argue that customization tends to work its way from the customer back up the supply chain. They define a typology of five strategies that includes pure standardization, segmented standardization, customized standardization, tailored customization and pure customization. No one type is considered as the mass customization strategy, but a trend toward customized standardization is discerned.

A value chain perspective is implicit in Ross's (1996) five approaches to providing mass customers with a high degree of choice. Ross doesn't describe the categories but does include example products. At one end of the spectrum is core mass customization, an approach in which the customer can modify core elements (e.g. NBIC bicycle - discussed later). Then comes post-product customization where a customizing service converts a standard product into a customized one (e.g. business software). Below this is mass retail customization where customization takes place at the retailer (e.g. spectacles), followed by self-customizing products (e.g. PC software, mobile phones), and lastly high variety push (e.g. wrist watches). Ross also talks about levels of customization ability, with the lowest being cosmetic, which he classes as the easiest type and includes offering a number of colours, surface finishes or materials. A step up in level is selectable functional options and the third and highest level is core customization. Ross does not cross-link these to the five approaches identified.

Specifically in the context of the automotive industry, Alford et al. (2000) put forward three distinct strategies of customization - core, optional and form customization - in which the value chain perspective is also apparent. In core customization the customer is involved in the vehicle design process such as occurs in low volume specialist vehicles. In optional customization the customer is able to choose their vehicle from a very large number of options. In form customization customers are able to have limited changes or enhancements made to the actual vehicle which could be dealt with at the dealer or retailer.

Duray et al. (2000) categorize mass customizers by both the stage along the value chain at which customization appears to take place and the customizing method, which centres on product 
architecture. The work of Lampel and Mintzberg is drawn on to identify the stage along the value chain and the work of Ulrich and Tung (1991) is used for product architecture. Four categories of mass customizes are named - Fabricators, Involvers, Modularizers and Assemblers. In terms of the modularity categories, fabricators and involvers can use 'component sharing' or 'cut-to-fit' modularity, while modularizers and assemblers can use 'component swapping', 'mix', 'bus', and/or 'sectional' modularity.

A detailed review of the MC literature, including some mentioned here, is provided by $\mathrm{Da}$ Silveira et al. (2001). They generate eight levels of mass customization ranging from pure customization to pure standardization. Again a value chain perspective underpins their scheme.

A value chain perspective does not underscore the categories of Gilmore and Pine (1997) who introduce four distinct approaches to customization, which they call collaborative, adaptive, cosmetic, and transparent, with collaborative being the one most often associated with the term mass customization. The underlying dimensions for this scheme are whether the customer is active or passive in prompting the customization and whether the core product is customized or not. The product itself is not changed in adaptive or cosmetic customization.

\subsection{Progress in developing $M C$ configurations models}

The establishment of dependencies between organisational characteristics, organisational strategy and the business environment leads to the development of configurations models (Bozarth and McDermott 1998). The organisational characteristics addressed by a configuration model can encompass organisational structure, manufacturing process and control technology, design technology, supplier management, customer service techniques, quality management methods, and such like.

Many researches propose or describe enabling practices and technologies, as summarised in the literature review by Da Silveira et al. (2001). However, only Duray et al. (2000) make progress towards configuration models by searching for correlations between MC strategy and three technologies - design technology, manufacturing technology (including process layout and process control method) and administrative technology.

\subsection{Application of classification schemes to case studies}

In order to compare the classification schemes identified above and to consider their suitability and potential for developing configuration models, they are applied to five case studies summarised below. All of these enterprises offer at least some of their customers the opportunity to have a product 'any time they want it, anywhere they want it, any way they want it' (Hart 1994) and in any volume they want it. This confirms them as operating broadly in the MC environment.

\section{National Bicycle Industrial Company (NBIC)}

Kotha (1995) describes how NBIC custom manufactured high-end bicycles with a two week delivery time for the Japanese market, and then expanded it to the international market with a three week delivery time. In 1987 the company set up a second facility next to its mass production plant and introduced a revolutionary production system, named the Panasonic Order System (POS), whereby customers could, by visiting a company dealer, choose from approximately 8 million variants encompassing model type, colour, frame sizes, and other features. By 1992 around 70,000 bicycles were custom made through this facility. The customer was measured in a dealership, where they also selected the model type, colour scheme, and other features. The bicycle dealer completed a form and faxed it to the control room of the custom-made factory. At the factory the details were transferred into the host computer, each order being given a unique bar-code label, which travelled 
with the bicycle to instruct and control each stage of manufacturing. The manufacturing resources were developed and built exclusively for use in the custom-factory. To begin the manufacturing process a CAD system generated a blue print of the bicycle's frame and other structural details. Tubing for frame and forks were measured and held by computer-assisted machines for manual cutting. Automatic alignment equipment enabled them to be tack welded and then brazed by automatic brazing machines. The geometry of each frame was checked automatically against its specification using a 3D measuring machine. Overhead conveyors carried the frame and forks to surface cleaning and painting. Preliminary painting by robot preceded finishing by two skilled workers. Before final assembly the customer's name was printed or engraved on the frame or handlebar stem. A bicycle was assembled by a skilled person in one of three stations, taking about 30 minutes. The bicycle was then boxed and sent to holding areas awaiting delivery, from where they were shipped, generally the same day, to dealers to be passed to the customer.

\section{Motorola Bandit pagers}

A number of sources (Eastwood 1996, Pine 1993) describe how Motorola began customizing their Bandit pager in the early 1980's, to offer customers up to 29 million product combinations encompassing hardware and software configurations. Production was consolidated in one factory whereas before the project it had been divided between a number of facilities. Customers select their options and a salesperson enters the specification into a computer system. It is then transmitted to the company systems and on to the assembly process. The facility could accept orders for single pagers in any sequence. The finished product was then shipped to the customer.

\section{Bicycle manufacturer}

A European mass manufacturer of bicycles is prepared to customize if expected volumes are sufficient, resulting in customization being limited to large retail customers. It customizes a product for a period of time, not for a fixed volume. Once the product is specified and designed, that customer can order it as if it were a catalogue model - any time and in any volume. The model is not available to other customers. Customization requests are not handled through the routine ordering mechanism, but via a customer liaison point. On the manufacturers side this could be the Product Manager or a member of the sales team. The dialogue is not scripted and the product development process is not fixed. Once the customized product is designed and made available to the customer, it is assigned a product number and the customer places orders as if it were for any other product from the range. The company does not have separate customization resources. Product development, sourcing, manufacture, warehousing and delivery of customized products are undertaken by the same resources as for catalogue products. Orders for customized products are treated just as those for non-customized products and in this company's case the preferred option is to pick from finished stock rather than manufacture-to-order. Consequently, sales of customized orders are forecast and purchasing and production planned accordingly, as for catalogue models. Other than for graphic transfers that are used as part of the colour scheme, the company does not source new components for a customization. A typical customization involves selecting one of the standard ranges and changing the mix of components and the colour/graphics.

\section{Computer assembler}

This company is a service provider and mass assembler of computer systems. All computers are assembled-to-order to a configuration selected by the customer. Customers are given considerable choice in the configuration by means of a catalogue that is in the form of a product configurator, and very rarely do customers request configurations outside of this catalogue. Two factors result in 
a very large variety of products being assembled: the permutations of product configurations enabled by the components on offer and the large diversity in customer requirements. Indeed, approximately $20 \%$ of computers assembled have a unique specification. All components are validated before being offered in the catalogue, which includes tests for interactions between components.

Customers place orders via telephone or web and can check on the status of the order at any time, again by telephone or web. The supply and assembly systems are organised so as to cope with the variety on offer. Assembly begins with picking components from stock for a computer and each is assembled as it moves along a bench. All computers then go into a testing and 'burn-in' area where they are taken through a cycle that is tailored to their specification before proceeding to packaging and despatch. Although assembly time and duration of tests vary with the configuration no restriction is placed on the sequence of computers through the assembly and test areas since the processes can tolerate the variation.

\section{Commercial vehicle manufacturer}

This company is a mass manufacturer of commercial vehicles with several production facilities. The commercial vehicle is designed to be configurable with many options. Each vehicle passing through a plant is assigned to a customer or a dealer and the specification of the vehicle will have been selected by that customer or dealer. Some options, referred to as specials, can involve a part finished vehicle being completed by a sub-contractor. The motivation for creating a new special option is a customization request from a large (fleet) customer. The design is engineered, necessary components sourced and tasks added to the production line. If necessary a sub-contractor is selected and involved at the design stage. Due to the wide range of customizations the development time is variable. Once proven, a special option is added to the catalogue and made available to other customers.

\subsubsection{Classification of case studies}

Each classification scheme is now applied to each of the case studies. Table 1 identifies the categories for each case study under each scheme. These findings are justified below.

\section{Lampel and Mintzberg}

By fabrication and painting of the frame, NBIC is practicing tailored customization. However a significant aspect of the customization is the selection of components for gears, brakes etc, which accords with customized standardization.

The bicycle manufacturer is a mix of customized standardization and tailored customization. If painting is treated as an assembly task, then, as in customized standardization, a special is made from standardized components and assembly is customized while fabrication is not and the product is constructed from a central core. But as in tailored customization customers are presented with a prototype (which in this case is a catalogue model) to which modifications are made.

The computer company matches customized standardization as all customization takes place at the assembly stage.

The commercial vehicle manufacturer does not fit any category fully but has aspects in common with tailored customization and pure customization. As with tailored customization, the base vehicle is the prototype and customers request modifications, usually in the form of additions, but sometimes they wish parts to be removed. Unlike tailored customization there can be significant engineering effort to create the customization. This engineering effort brings it into the realm of pure customization and both sides are involved in decision-making, but the use of the base model prevents it from qualifying as pure customization only. 


\section{Ross}

All of the case studies are judged to qualify as core customizers. However, in the case of the commercial vehicle manufacturer, the use of a contractor to complete a part finished or fully finished vehicle taken from the production line also matches post-production customization.

\section{Alford et al.}

Four of the case studies most closely fit the optional customization category. For NBIC to be treated as an optional customizer the fabrication of the frame to size needs to be considered the same as painting, which Alford et al. classify as optional customization.

The commercial vehicle is a core customizer.

\section{Duray et al.}

There is some uncertainty in classifying NBIC against Duray's scheme. NBIC's practice of sizing the frame to the customer could be viewed as involving the customer at the fabrication stage, hence they could be classed as a fabricator. But this is the category into which customizers of unique designs reside, which overstates NBIC's approach. They could be classified as an involver if the frame cutting is thought of as a standard component that has been designed but not cut before the order is taken. They could also be labelled a modularizer, since they have applied modular thinking to the product and the frame building task also has a large element of assembly. At this time NBIC are categorised as an involver.

The bicycle manufacturer is classified as an assembler, though an argument could be made for treating them as a modularizer since the bicycle has evolved into a standardized and largely modular product.

The commercial vehicle company is a fabricator and the computer assembler is an assembler. There is uncertainty in allocating Motorola to either the modularizer or assembler categories.

\section{Da Silveira et al.}

Using Da Silveira's scheme the commercial vehicle manufacturer could be said to fit the additional custom work category as nearly all special vehicles are standard vehicles that are then adapted. However the extent of design effort per new variant is significant and hence they fit more closely with the design category.

NBIC most closely matches the fabrication category. Motorola, the computer assembler and the bicycle manufacturer fit the assembly category

\section{Gilmore \& Pine}

All case studies fit into the collaborative customizer category.

\section{Table 1: $\quad$ Classification comparison}


Appears in: International Journal of Production Economics, Volume 85, Number 3, pp 289 - 304, Published by Elsevier Science B.V.,

\begin{tabular}{llllll}
\hline & NBIC & Motorola & $\begin{array}{l}\text { European } \\
\text { Bicycle }\end{array}$ & Computer & $\begin{array}{l}\text { Commercial } \\
\text { vehicle }\end{array}$ \\
\hline $\begin{array}{llll}\text { Lampel and } \\
\text { Mintzberg }\end{array}$ & $\begin{array}{l}\text { Tailored } \\
\text { customization }+ \\
\text { Customized } \\
\text { standardization }\end{array}$ & $\begin{array}{l}\text { Customized } \\
\text { standardization }\end{array}$ & $\begin{array}{l}\text { Customized } \\
\text { standardization } \\
\text { Tailored } \\
\text { customization }\end{array}$ & $\begin{array}{l}\text { Customized } \\
\text { standardization }\end{array}$ & $\begin{array}{l}\text { Tailored } \\
\text { customization }+ \\
\text { Pure } \\
\text { customization }\end{array}$ \\
Ross & $\begin{array}{l}\text { Core } \\
\text { customization }\end{array}$ & $\begin{array}{l}\text { Core } \\
\text { customization }\end{array}$ & $\begin{array}{l}\text { Core } \\
\text { customization }\end{array}$ & $\begin{array}{l}\text { Core } \\
\text { customization }\end{array}$ & $\begin{array}{l}\text { Core } \\
\text { customization }+ \\
\text { Post-product } \\
\text { customization }\end{array}$ \\
Alford et al. & Optional & Optional & Optional & Optional & Core \\
Duray et al. & Involver & Assembler & Assembler & Assembler & Fabricator \\
Da Silveira et \\
$\begin{array}{l}\text { al. } \\
\text { Gilmore and } \\
\text { Pine }\end{array}$
\end{tabular}

\subsection{Discussion of $M C$ classification schemes}

To provide the basis for configuration models a classification scheme should group together enterprises that share similar organisational solutions and keep separate those that have diverse or conflicting needs. In this respect the above schemes have limitations. The schemes do not distinguish or differentiate key characteristics. Three comparisons illustrate these points:

- $\quad$ NBIC, Motorola and the computer company all make-to-order unique products in lot sizes of one. In all cases manufacturing is triggered by a customer's order, and apart from the frame in the case of NBIC, all components are off-the-shelf. Consequently they can be expected to share characteristics, but in only three of the six classification schemes are they placed in the same classification. In the other three schemes, only Motorola and the computer company are placed in the same classification.

- The European bicycle company and the commercial vehicle manufacturer both apply a policy of customizing in anticipation of repeat orders and both give customers considerable leeway in when and in what quantity customers can re-order products. In addition both create customized products by adapting existing variants in the catalogue, and both consequently have to ensure that customers customized designs remain viable as changes are made to catalogue products. Although in other respects these companies differ, in particular in how they organize manufacturing and assembly, and acknowledging the design effort per customized vehicle can be considerably greater than per bicycle, nevertheless it is likely they could benefit from similar organizational solutions for the tasks they have in common. While there is overlap in the classification of these two companies against some of the schemes, the overlap is due to ambiguities in the interpretation of the extent of customization rather than due to organizational similarities.

- The European bicycle company has approached customization in a different way to NBIC, to an extent where the technologies it can use to achieve high performance are different from those NBIC has employed. However, in all but one scheme - Duray et al - they are assigned the same classification. If the European bicycle company shifted to customizing orders for single bicycles rather than in bulk as it does at present, it would be expected that it could learn much from NBIC. Even when moving to one-at-time customization it would remain an assembler in Duray's scheme while NBIC is an involver. 
Of the six classification schemes, Gilmore and Pine's is the most straightforward to apply. There is a degree of uncertainty in assigning the cases with the other five schemes. The ease of applying this scheme is partly due to it not taking a strongly value chain perspective. However, its focus is wider than mass customization and consequently, as found here, enterprises with notable differences are grouped together. The scheme is not therefore a strong candidate as the starting point for configuration development.

It is useful to analyse the value chain perspective further. The uncertainties in applying the approaches that adopt a value chain perspective stem from the premise used implicitly in these schemes that there is a single point of customization. Reality is different. A product can have some features that involve customized fabrication and other features that entail customized assembly. Take as an example a customized bicycle from NBIC. While the frame is the largest item, a typical model has approximately a hundred other component types (i.e. counting spokes as one component type or a rear Derailleur gear set as another component type). The selection of these components is a significant part of customizing a bicycle, but unlike the frame and forks, NBIC will not fabricate them.

The weakness of the value chain classifications is that it under-emphasises two key distinguishing factors and it omits a third factor. The two factors given insufficient prominence are:

- temporal relationships between activities, in particular between design and validation activities and other order fulfilment activities; and

- whether the technological resources used in order fulfilment are fixed or modifiable.

The first of these factors is not explicit but is detectable in all of the value chain based classifications, since all have at one extreme a category in which considerable design effort occurs per customer, and at the other extreme a category in which design is complete before the first purchase. The temporal relationship between activities such as design, fabrication and assembly is a common way of differentiating non make-to-stock manufacturers, using categories such as assemble-to-order, make-to-order and engineer-to-order (Slack et al. 1998, Amaro et al. 1999). From the case studies there are three temporal relationships to be accounted for. Firstly there is design and validation per product family where these processes are completed before any customer places an order for a product. Secondly there is the per order situation when the customer is involved during each order fulfilment cycle, i.e. the customer's product is designed and engineered between order taking and delivery. Thirdly there is the per product relationship where design and validation take place at the prompting of the customer but prior to (repeat) orders being placed by the customer for that product.

The second factor - fixed or modifiable order fulfilment resources - is implicit in the schemes but almost hidden. It is most visible in the scheme of Da Silveira et al. who include the category 'additional custom work' but this scheme does not carry it to its logical conclusion, which is that customizers either restrict the extent of customization to that which they can fulfil within the envelope of their present materials supply, processing and delivery resources or they modify them, such as by investing in additional or different process technology or engaging a new supplier or subcontractor so as to enable the manufacture of the customized product.

The factor which the classification schemes reviewed above have omitted is whether an enterprise customizes a product on a once-only basis or whether they customize on a call-off basis, in which they accept a customization commission if repeat orders are likely, the latter being similar to 'Repeat Business Customizers' identified by Amaro et al (1999). The call-off approach is typical for suppliers to the so-called 'mass merchants' (McDermott and O'Connor 1995) whose desire for product differentiation influences their buying decisions and leads them to make requests for customized orders, customized lot sizes, customized packaging, and customized shipping schedules. 
For example, they dictate when and how a promotion is run and the type of promotion specials required, such as an additional spare part or a gift item in a package.

\section{Identification of modes for MC operations}

Having identified these three important distinguishing factors, we now use them in the identification and development of fundamental primary operations modes for Mass Customization. The primary modes are identified by linking the distinguishing factors discussed above to an operations process model, shown in Figure 1. The model has six processes that are fundamental to Mass Customization:

- Order taking co-ordination: this process manages the dialogue with the customer, receiving and interpreting the customers' wishes, coding them for verification by the customer, finding a product solution for the customer and generating the details of the order.

- Product development and design: this process handles the design for the customer. Compliance with external and internal standards is within its scope.

- Product validation and manufacturing engineering: this process is responsible for confirming the manufacturability of the design and its translation into a set of manufacturing procedures and rules. It will typically generate the bill of materials for the customized products and provide guidelines on routing and processing instructions.

- Order fulfillment management. this process manages the order fulfillment value adding chain, including the supply chain. It interacts with the order co-ordination process, informing it of when it can complete an order and schedules and controls the order fulfillment activities.

- Order fulfillment realisation: this process encompasses the activities executed in the manufacture of products, and includes supplier activities, internal manufacturing processes and delivery activities.

- Post order process: these are activities that (may) follow the completion of an order, such as maintenance, warranty claims, technical guidance, etc.

The process model enables the distinguishing factors identified and described in the earlier analysis to be operationalised. Here we identify the principal core processes that are affected. The first factor - temporal relationships - dictates when the processes are executed relative to each other. The product design and product validation processes can be executed per product family, per product or per order (as described in section 2.3). The second factor - fixed or modifiable resources - is mapped onto the order fulfilment realisation process. The third factor - whether an enterprise customizes a product on a once-only basis or whether they customize on a call-off basis - has a bearing on temporal relationships (i.e. product design and validation are performed only at the inception of a customized product) and on how the processes are implemented, such as the control methods used by order fulfilment management. 


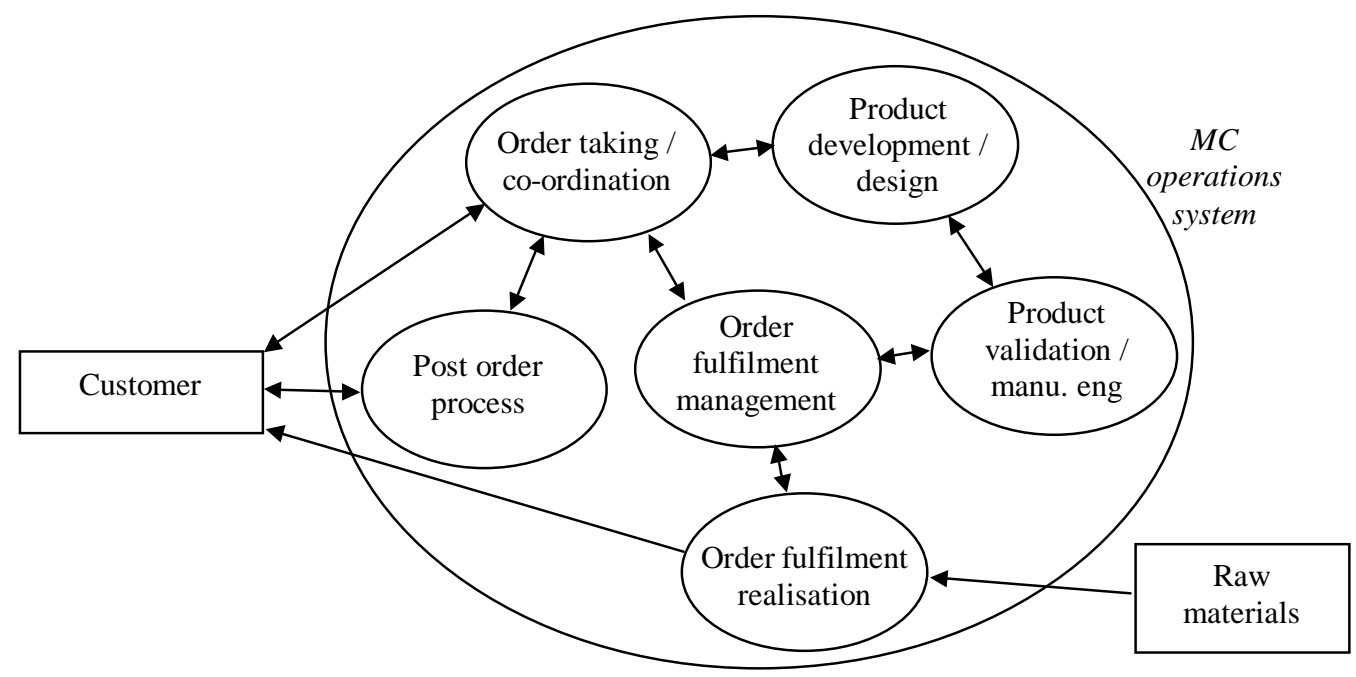

Figure 1: Operations processes in an MC system

\subsection{Fundamental modes for $M C$}

Linking the permutations of the distinguishing factors noted earlier with the MC Operations process model discussed above leads to the development of the fundamental operational models for MC. Not all permutations are feasible. Although there are three temporal dimensions and two dimensions for the other two factors, making a total of twelve theoretical configurations, many of these are infeasible. For example, when the product range is designed prior to orders being taken, it is assumed the order fulfilment resources are fixed and there is no difference between a one-off and a repeat order.

Five fundamental modes, A to E, can be identified. These are shown diagrammatically in Figure 2. They are named and described below and summarised in Table 2:

\section{Mode A : Catalogue MC}

A customer order is fulfilled from a pre-engineered catalogue of variants, produced using standard order fulfilment processes. In this mode the engineering of products is not linked to orders, but completed before orders are received. Customers select from a pre-specified range and the products are manufactured by the order fulfilment activities that are in place. Likewise the order fulfilment activities are engineered ahead of an order being taken.

\section{Mode B : Fixed resource design-per-order MC}

A customer order is fulfilled by engineering a customer specific product, produced through standard order fulfilment processes. The customer places one order for the product and there is no expectation of repeat orders. In this mode there is some degree of product engineering for each order, unless a customer's wishes happen to match a previous order in which case the product design is reused. Because the order fulfilment process is standard all designs must be suitable for the process. Therefore it is important the product development process is aware of the process capabilities. 


\section{Mode C : Flexible resource design-per-order MC}

A customer order is fulfilled by engineering a customer specific product, and produced through modified order fulfilment processes. The customer places one order for the product and there is no expectation of repeat orders. In this mode products are engineered per order and the order fulfilment process may be modified per order.

\section{Mode D : Fixed resource call-off MC}

A customized product is designed for a customer, to be manufactured via standard order fulfilment processes in anticipation of repeat orders. At the prompting of a customer a product is designed that can be manufactured through the standard order fulfilment process, and the customer can order the product at any time.

\section{Mode E: Flexible resource call-off MC}

This mode is the same as Mode D except that the order fulfilment activities are modifiable. A customer order is fulfilled by engineering a customer specific product, and produced through modified order fulfilment processes. There is an expectation of repeat orders.
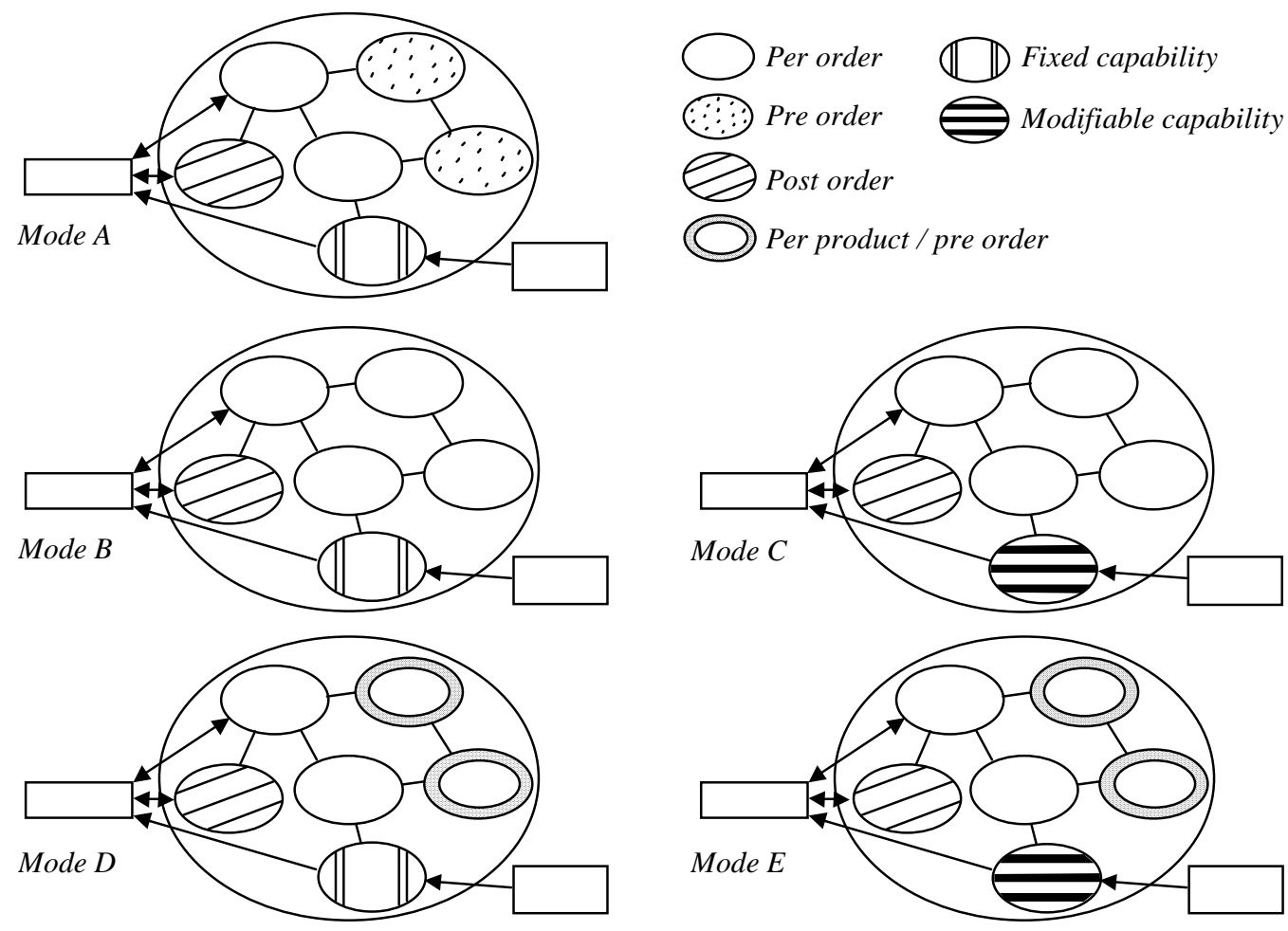

Figure 2: The Five Fundamental MC Modes 


\begin{tabular}{|c|c|c|c|c|c|}
\hline & A & B & C & D & E \\
\hline & Catalogue & $\begin{array}{l}\text { Fixed } \\
\text { resource } \\
\text { design- } \\
\text { per-order } \\
\text { MC }\end{array}$ & $\begin{array}{l}\text { Flexible } \\
\text { resource } \\
\text { design- } \\
\text { per-order } \\
\text { MC }\end{array}$ & $\begin{array}{l}\text { Fixed } \\
\text { resource } \\
\text { call-off MC }\end{array}$ & $\begin{array}{l}\text { Flexible } \\
\text { resource } \\
\text { call-off MC }\end{array}$ \\
\hline Temporal relationship - Product design & Per family & Per order & Per order & Per product & Per product \\
\hline Product validation / manu eng & Per family & Per order & Per order & Per product & Per product \\
\hline Once-off / Call-off & - & $\mathrm{O}$ & $\mathrm{O}$ & $\mathrm{C}$ & C \\
\hline $\begin{array}{l}\text { Fixed / Modifiable order fulfilment } \\
\text { resources }\end{array}$ & $\mathrm{F}$ & $\mathrm{F}$ & M & $\mathrm{F}$ & M \\
\hline Classification of case studies & $\begin{array}{l}\text { NBIC, } \\
\text { Motorola, } \\
\text { Computer, } \\
\text { Commercial } \\
\text { vehicle }\end{array}$ & & & $\begin{array}{l}\text { European } \\
\text { Bicycle }\end{array}$ & $\begin{array}{l}\text { Commercial } \\
\text { vehicle }\end{array}$ \\
\hline
\end{tabular}

\subsection{Classiffing the case studies by mode}

Three of the case studies comply with the requirements of Catalogue MC (Mode A) as listed in

Table 2. The computer assembler, Motorola pager and NBIC all design and engineer their product range prior to accepting orders, hence they operate on a per family basis. Their order fulfilment resources are matched to the product range, hence they are fixed and they treat one-off and repeat orders alike.

The bicycle manufacturer and commercial vehicle manufacturer both design and engineer a customised product on a product by product basis, ahead of it being manufactured. Both take on a customized product in anticipation of repeat orders. They differ in whether they modify their order fulfilment resources for a customized product. The bicycle manufacturer constrains its customers to the capabilities of its existing component range and manufacturing activities (Mode D), whereas the commercial vehicle manufacturer is prepared to modify and extend its order fulfilment resources by taking on new suppliers / contractors or altering / adding processes that are performed in-house or by existing contractors (Mode E).

\section{Discussion}

These modes add to the knowledge on the 'content' of mass customization - what MC is and what the activities within $\mathrm{MC}$ are. Given that $\mathrm{MC}$ is an emerging paradigm, content based research is essential (Thietart and Wauchope 2001). However, the modes also forge a route for exploring the 'process' of MC and pave a way towards understanding issues including why enterprises evolve into one mode rather than another and how the infrastructure and processes within an enterprise must change if it is to move between modes.

It is expected that a mass customizing enterprise will comply with at least one of the modes. However, a company can operate in more than one mode, even in regard to the same product family. For example, the commercial vehicle manufacture has one product family but it operates in mode $\mathrm{E}$ (Flexible resource call-off MC) for a proportion of its customers and for the remaining customers it operates in mode A (catalogue MC) hence this enterprise is listed under both modes in 
Table 2. Some parts of its organisation are involved solely in mode E. This demonstrates the feasibility of multi-modal operations.

Any classification is necessarily an approximation of reality, balancing the level of detail necessary to capture important characteristics against the need for a tractable scheme that is not overly complex. It depends also on where the boundaries of the domain are set. For instance, contract manufacturing has not been considered in the modes scheme. As the modes are further researched the applicability of the concepts to the contract manufacturing business model can be explored. It is possible that when contract manufacturing is considered the taxonomy may need to be extended.

A feature of the modes is the commonality between them. Some organisational characteristics can be expected to be beneficial to several modes. For example, enterprises that conform to Mode $\mathrm{D}$ or $\mathrm{E}$ engineer a product with customer involvement and then manufacture that product as and when necessary. Mode E enterprises have the added challenge of scoping and implementing modifications to their order fulfilment resources and therefore their organisation will differ from Mode D companies. However Mode D and E companies can be expected to share some organisational characteristics and technologies that are relevant to their common practices. Therefore, although the mode classification assigns the European bicycle manufacturer and the commercial vehicle manufacturer to different modes, the modes scheme expects technologies that are beneficial to one can be beneficial to the other.

A question to address is whether each mode is an end in itself, or whether one or more of the modes are steps toward other modes? At this time it is expected that all five modes are legitimate stand-alone modes rather than intermediate stages. For example, Mode A in which customers select from a catalogue of pre-engineered options is a mode that would be difficult to implement by enterprises who supply mass merchants (McDermott and O'Connor 1995). Mass merchants are keen to differentiate themselves from other sales channels and one approach is to stock products not available elsewhere. Consequently mass merchants can frequently push suppliers to go beyond their catalogue significantly. For these enterprises Mode D or E is preferable and attempting to operate in Mode A would lead to conflict and inefficiencies. In the case of the commercial vehicle manufacturer, even though its customers are not mass merchants and so do not seek differentiation for differentiations sake, it is unlikely to switch from Mode E. Its customers' needs are too diverse to be predicted and the cost of developing product variants before an enquiry does not make it worthwhile to attempt to do so, as the risk of wasted investment is high.

The five modes can be interpreted from the two viewpoints emerging of mass customization discussed in the introduction. The first is that to be a mass customizer an enterprise should exhibit characteristics such as having a pre-engineered product range and an order fulfilment system ready and capable of manufacturing and delivering any variant in the range. Mode A encapsulates this viewpoint. The second is that $\mathrm{MC}$ is an ideal state of operation, in which customers are given the opportunity of having any product, any time, anywhere, any way they want it. Modes B and C can be interpreted as carrying through this ideal. The last two modes (D and E) blend the two viewpoints and they reflect the richness of reality in which customers demand customization but the diversity of their needs precludes pre-determining product options. Enterprises that customize on a once-off or on a call-off basis belong to one of these mass customization modes (B to E) if their performance with respect to speed, cost, quality, responsiveness, etc., merits the distinction. The performance criteria that differentiate customizing enterprises from mass customizing enterprises have yet to be formulated in a manner similar, for example, to how the six sigma threshold distinguishes enterprises on quality grounds (Harry 1994). It is probable that the threshold dividing customizers from mass customizers is not a universal absolute but dependent on 
market environment and will shift over time. The performance criteria themselves are an important area for future research as are the technologies for attaining them.

\section{The MC modes as a basis for MC configuration models}

As with other classification schemes, for the modes to be useful as configurations models there needs to be dependency between them and organisational characteristics. We expect the modes classification to be useful in areas including organisational structure, information management, quality assurance and control, product design and validation technologies, and supplier management. To illustrate this we contrast the information infrastructure of two modes. This has been informed by field observation undertaken by the authors.

\subsection{Information needs for two different modes}

Differences in the information requirements of each mode reveal themselves in terms of the types of information stores used in each mode, the communication links between the six processes and the information transformations within the six processes. The first two of these can be made explicit by developing the process diagram. This has been done for Mode A (Catalogue MC) and Mode B (Fixed resource design-per-order MC) in Figures 3 and 4.

Some of the links and stores are common to both modes (and may be common to other modes) and in many instances the links and stores have the same role, but for some they are different. For example, in the upper left of each diagram a customer expresses their wishes to the order coordination process which in turn codes their wishes for the purpose of customer verification (Marked as item 1). The customer's coded wishes are communicated to the product design process but, whereas in Mode B this is to facilitate designing a product for that customer, in Mode A the link is for the purpose of providing market intelligence to the design function (because in Mode A customers are selecting from a pre-designed catalogue of products, but any opinions or comments they have about them may be useful for the development of future products).

Differences between the modes are most obvious on the right side of each diagram. In Mode A, the product design and product validation processes build catalogues of designs and product recipes respectively (items 2 and 3). The product design catalogue is searched by the order taking process on behalf of each customer as is the catalogue of product recipes by the order fulfilment management process. Feeding into the product validation process is information on the capabilities of the order fulfilment realisation process, provided by the order fulfilment management process (item 4). This information is necessary to enable the product validation process to create valid product recipes.

More links and data stores appear in this area of Mode B. In this mode the product design process generates a product design for each customer (represented by data store 5) and the product validation process generates a recipe for that product (represented by data store 6 ). The design and recipe catalogues that were in Mode A are still present but in Mode B they are for reference by the design and validation processes alone and are referred to as libraries (items 7 and 8). As in Mode A, the product validation process must be aware of the capabilities of the order fulfilment resources, but in this mode an additional link is required. It is advantageous for the product validation process to be aware of short term resource (un)availabilities - such as a supplier being put on hold for quality reasons - hence the order fulfilment management process generates an up-to-date log of availabilities (item 9). 


\section{Conclusions}

A strength of the modes taxonomy is that it has emerged from observation and analysis. The case study approach has allowed the limitations of existing classification schemes to be uncovered and identified. The mode taxonomy builds on the existing schemes but has not been constrained by them. A value chain perspective dominates the earlier schemes but has not been adopted for the mode taxonomy. Instead the modes are formed around a process oriented model with six core processes.

Field evidence of mass customization enterprises, particularly in the form of reported case studies, is relatively sparse. Consequently the relative frequency of the different modes in MC businesses is not as yet apparent. Further validation of the modes and the completeness of the scheme will be judged against emerging practice.

An important line of research will be the identification and quantification of key performance thresholds for qualifying an enterprise as a mass customizer.

\section{Acknowledgements}

We would like to acknowledge UK EPSRC (project GR/N11742/01) for their support of this work. In addition we would like to record our thanks to our colleagues at Oxford University - Janet Efstathiou, Claudia Mchunu, Aruna de Alwis - and our consortium members.

\section{References}

Amaro, G., L. Hendry and B.K. Kingsman, 1999, Competitive advantage, customisation and a new taxonomy for non make-to-stock companies, International Journal of Operations and Production Management 19, 349-371.

Alford, D., P. Sackett and G. Nelder, 2000, Mass customisation - an automotive perspective, International Journal of Production Economics 65, 99-110.

Bozarth, C. and C.M. McDermott, 1998, Configurations in manufacturing strategy: a review and directions for future research, Journal of Operations Management 16, 427-439.

Da Silveira, G., D. Borenstein and F.S. Fogliatto, 2001, Mass customization: Literature review and research directions, International Journal of Production Economics 72, 1-13.

Davis, S.M., 1987, Future Perfect (Addison-Wesley, Reading, MA).

Duray, R., P.T. Ward, G.W. Milligan and W.L. Berry, 2000, Approaches to mass customization: configurations and empirical validation, Journal of Operations Management 18, 605-625.

Eastwood, M.A., 1996, Implementing mass customization, Computers in Industry 30, 171-174.

Gilmore, J.H. and B.J. Pine, 1997, The four faces of mass customization, Harvard Business Review 75, 91-102.

Hart, C.W.L., 1994, Mass customization: conceptual underpinnings, opportunities and limits, International Journal of Service Operations 6, 36-46.

Kotha, S., 1995, Mass Customization: Implementing the emerging paradigm for competitive advantage, Strategic Management Review 16, 21-42.

Lampel, J. and H. Mintzberg, 1996, Customizing customization, Sloan Management Review 38, 21-31.

MacCarthy, B., 2001, Multiple perspectives on mass customization: definitions, concepts and classifications, Presented at 2001 World Congress on Mass Customisation and Personalisation (Hong Kong).

MacCarthy, B., P.G. Brabazon and J. Bramham, 2002, Key Value Attributes in Mass Customization, in C. Rautenstrauch, R. Seelmann-Eggbert and K. Turowski, eds., Moving into Mass Customization: Information Systems and management Principles, (Springer) 71-89.

McDermott, C.M. and G.C. O'Connor, 1995, Managing in the age of the mass merchant, Business Horizons 38, 64-70.

Pine, B.J., II., 1993, Mass Customization: The new frontier in business competition (Harvard Business School Press, Boston, MA).

Ross, A., 1996, Selling uniqueness - Mass customisation: the new religion for manufacturers?, Manufacturing Engineer 75, 260-263

Silvestro, R., 2001, Towards a contingency theory of TQM in services: how implementation varies on the basis of volume and variety, International Journal of Quality and Reliability Management 18, 254-288.

Slack, N., S. Chambers, C. Harland, A. Harrison and R. Johnston, 1998, Operations Management (Pitman)

Thietart, R.-A. and S. Wauchope, 2001, Doing management research: a comprehensive guide (Sage Publications Ltd).

Tu, Q., M.A. Vonderembse and T.S. Ragu-Nathan, 2001, The impact of time-based manufacturing practices on mass customization and value to customer, Journal of Operations Management 19, 201-217.

Harry, M.J, 1998, Vision of Six Sigma: a road map for breakthrough (Sigma Publishing Company) 